Review

Somnologie $2021 \cdot 25: 89-98$ https://doi.org/10.1007/s11818-021-00306-8 Accepted: 19 February 2021

Published online: 19 May 2021

(c) The Author(s) 2021
Jens G. Acker ${ }^{1,2} \cdot$ C. Becker-Carus ${ }^{3} \cdot$ Antje Büttner-Teleaga $^{4,5} \cdot$ Werner Cassel $^{6}$. Heidi Danker-Hopfe ${ }^{7}$ Alexander Dück ${ }^{8}$ Corinna Frohn ${ }^{9} \cdot$ Holger Hein $^{10}$. Thomas Penzel ${ }^{11}$. Andrea Rodenbeck ${ }^{12}$. Till Roenneberg ${ }^{13}$. Cornelia Sauter ${ }^{14}$. Hans-Günter Wee $\beta^{15}$. Josef Zeitlhofer ${ }^{16} \cdot$ Kneginja Richter $^{17,18}$

'Clinic for Sleep Medicine Bad Zurzach and Zurich Airport, Bad Zurzach, Switzerland; ${ }^{2}$ Institute for Medical Management and Health Sciences, Bayreuth University, Bayreuth, Germany; ${ }^{3}$ General Psychology, Somnology, Institute for Psychology, University of Münster, Münster, Germany; ${ }^{4}$ Institute for Cognitive Sciences, Woosuk University, Samnye-up, Korea (Republic of); ${ }^{5}$ Department of Psychiatry, University of Witten-Herdecke, Witten, Germany; ${ }^{6}$ Sleep Medical Center, Philipps University Hospital, Marburg, Germany; ${ }^{7}$ Competence Center for Sleep Medicine, Charité-University Hospital, CC15-Benjamin Franklin Campus, Berlin, Germany; ${ }^{8}$ Center for Child and Adolescent Neurology, Clinic for Psychiatry, Neurology, Psychosomatics, and Psychotherapy, Bad Doberan Site, Rostock University Hospital, Bad Doberan, Germany; ${ }^{9}$ Bethanien Medical Center, Solingen, Germany; ${ }^{10}$ Sleep Medicine Practice and Laboratory, Reinbek/Geesthacht, Germany; ${ }^{11}$ Interdisciplinary Sleep Medicine Center, Charité-University Hospital Berlin, Berlin, Germany; ${ }^{12}$ Department of Sleep and Respiratory Medicine and Sleep Laboratory, Evangelical Hospital Göttingen-Weende, Göttingen, Germany; ${ }^{13}$ Institute and Outpatient Department for Occupational, Social, and Environmental Medicine, Ludwig-Maximilian University, City Center Campus, Munich, Germany; ${ }^{14} \mathrm{Clinical}$ and Health Psychologist, Somnologist (DGSM, ESRS), Competence Center for Sleep Medicine, Charité-University Hospital Berlin, Berlin, Germany; ${ }^{15}$ Interdisciplinary Sleep Center, Pfalzklinikum, Klingenmünster, Germany; ${ }^{16}$ Department of Neurology, Medical University of Vienna, Vienna, Austria; ${ }^{17}$ Sleep Outpatient Clinic of the University Department of Psychiatry and Psychotherapy, Paracelsus Medical University Nuremberg, Nuremberg, Germany; ${ }^{18}$ Sleep Competence Group, Institute for E-Counseling, Nuremberg University of Technology, Nuremberg, Germany

\title{
The role of actigraphy in sleep medicine
}

Behavior in the home setting plays an important role in many sleep-related disorders. Despite the availability of actigraphy, longitudinal disease and treatment courses are usually recorded using subjective reports (e.g., sleep logs/sleep diaries).

Actigraphy has been used for more than 60 years to objectively measure sleep-wake rhythms [1]. The procedure makes it possible to measure and evaluate movement and other parameters such as light exposure over a prolonged period of time.

In recent years, actigraphy has been increasingly used in the clinical setting. Modern medical actigraphs are more accurate and reliable due their improved piezoelectric motion sensors, lithium batteries, and enhanced storage capacities.

The German version of this article can be found under https://doi.org/10.1007/s11818021-00308-6.
Current devices are able to record motor behavior over periods of up to months. Their improved waterproofing and low weight make them suitable for prolonged use under natural conditions, even on moving surfaces (e.g., on ships) [2]. Thus, insight can be gained into the motor phenomena of activity and rest phases as well as of circadian rhythms.

Since the cost of wrist actigraphy is not reimbursed, this method has not enjoyed wide acceptance to date. The present article provides an overview of its main clinical applications (- Table 1 ).

If one puts the main measuring instruments used in sleep medicine in order of accuracy, modern actigraphs rank below the accuracy of polysomnography for the majority of variables measured. Their chief advantage lies in the cost-effective collection of objective data over prolonged periods of time, usually 7-14 days, under everyday conditions. Particularly when investigating insomnia, hypersomnia, and circadian rhythm disorders, longer measurement periods significantly improve validity [4]. For a correct assessment of the sleep onset spectrum, it is important to have a detailed knowledge of the different assessment procedures ( $\bullet$ Fig. 1$)$. This plays a special role, for example, in the assessment of insomnia patients, as there can be considerable discrepancies between sleep protocols and actigraphy findings.

\section{Actigraphs}

\section{Technical features}

Newer actigraphs record motion in up to three axes. The recorded data are usually processed in a frequency range of $0.25-3 \mathrm{~Hz}$ with band-pass filters before they are saved. As a general rule, the epochs used in actigraphy devices can be freely selected; in sleep medicine practice, they are usually 30 or $60 \mathrm{~s}$.

For adaptation of the scoring algorithms, empirical values or laboratory 
Table 1 Overview of investigation methods used in sleep medicine

\begin{tabular}{lll}
$\begin{array}{l}\text { Investigation } \\
\text { method }\end{array}$ & Advantages & Disadvantages \\
\hline $\begin{array}{l}\text { Sleep question- } \\
\text { naire }\end{array}$ & $\begin{array}{l}\text { Brief and economical to use } \\
\text { Low patient burden }\end{array}$ & $\begin{array}{l}\text { Recall bias } \\
\text { Limited reliability in some patient groups (children, dementia, mal- } \\
\text { compliance, language barriers/difficulties in understanding) } \\
\text { Partially relies on patient's ability for introspection }\end{array}$ \\
Sleep diary & $\begin{array}{l}\text { Documents day-to-day variability } \\
\text { Less bias than questionnaires } \\
\text { Records everyday behavior (home setting) }\end{array}$ & $\begin{array}{l}\text { Needs to be completed daily } \\
\text { Influenced by expectations }\end{array}$ \\
Actigraphy & $\begin{array}{l}\text { Objective information } \\
\text { Documents day-to-day variability } \\
\text { Records everyday behavior (home setting) }\end{array}$ & $\begin{array}{l}\text { Limited determination of sleep onset latency (SOL) } \\
\text { Higher costs compared to diary, problems regarding reimbursement } \\
\text { Additional diary-keeping is useful }\end{array}$ \\
\cline { 2 - 3 } $\begin{array}{l}\text { Polysomno- } \\
\text { graphy }\end{array}$ & $\begin{array}{l}\text { Gold standard for the diagnosis of numerous sleep disor- } \\
\text { Records actual sleep physiology, structure, quality, and } \\
\text { quantity }\end{array}$ & $\begin{array}{l}\text { High patient burden } \\
\text { High costs } \\
\text { Laboratory environment with first-night effect (altered sleep due to } \\
\text { the first night of polysomnography) } \\
\text { Unable to investigate sleep in context }\end{array}$
\end{tabular}

Table 2 The most important variables in the sleep diary and actigraphy report

Sleep diary/event Light off (sleep attempt starts)

marker Light on (sleep attempt ends)

Length of sleep attempt

Actigraphy

\section{Night:}

Sleep onset time

Sleep onset latency (SOL; reported bedtime to sleep onset time)

Sleep offset time

Sleep opportunity

Total sleep time (TST)

Night awakening (frequency, duration)

Sleep efficiency (TST/sleep opportunity)

Evaluation of ultradian rhythms [13]
Day:

Number of sleep episodes (naps, daytime sleep)

Percentage of daytime sleep in a $24-\mathrm{h}$ period

\section{Table 3 Suggested procedure for actigraphy in a sleep centre. (Adapted from [14])}

A: Initial consultation: the actigraphy device is issued at the sleep center

1. Use of the actigraphy device is explained

Event markers (marking bedtime and getting-up time) are demonstrated

2. Actigraphy directions for use (waterproofness, when to take the device off, etc., setting event markers, etc.) are explained and given to the patient

3. Keeping a sleep diary is discussed (recording sleep opportunity, sleep attempts, naps, etc.)

4. Sample actogram is explained (data recording process explained to patient)

5. Patient signs confirmation of receipt - patient provided with postage materials needed to return the device

\section{B: Preparing the follow-up visit (return of actigraph by post, data preparation)}

1. Downloading of raw data from actigraph

2. Data cleansing with sleep diary and event marker

3. Definition of sleep opportunity in software (main sleep phase, recording naps and daytime sleep episodes)

4. Selection of score settings, actogram printout, and datasheet

C: Follow-up consultation: discussion of findings with patients

1. Detailed daily history on sleep behavior

2. Determination of distorted perception regarding sleep times (e.g., mismatch between actigraphy and sleep diary in insomnia patients)

$D$ : Report generation, treatment planning

E: If necessary, follow-up of treatment outcome upon completion of therapy standards are used. The fact that there are as yet no standardized scoring recommendations negatively affects the objectivity of scoring and inter-rater reliability [6].

\section{Data acquisition and cleansing}

Wrist actigraphy usually measures daynight rhythms in daily life over $1-4$ weeks [7]. The ideally waterproof devices are worn on the non-dominant hand for $24 \mathrm{~h}$.

Additional information such as subjective total sleep time and quality can be recorded in a sleep diary. This can be used when discussing findings with the patient, in order to reconstruct everyday situations together with the patient and correlate these with the recorded actigraphy [8].

The use of actigraphy event markers as soon as a sleep attempt begins (eye closure, corresponding to actigraphy lightout) and ends (opening eyes in the morning, getting out of bed, corresponding to 
actigraphy light-on) has proven successful.

At the same time, sleep opportunity, which is often spent on other activities (e.g., watching TV, reading, eating) can be distinguished from actual sleep attempts. Nighttime sleep interruptions, such as visits to the toilet, are not marked by patients.

Thus, the actigraphy system is able to record the length of sleep, which is needed later to calculate the actigraphy variables (see $\bullet$ Table 2; [9]).

After downloading the actigraphy data, manual data cleansing should be performed. This makes it possible to significantly improve the actigraphy report [10]. Sleep-related data are then calculated, and an actogram generated with visualization of the day-night rhythm (see • Fig. 2). In clinical practice, automated analysis is generally used to this end $[11,12]$.

The graphic representation of the actogram (see example in • Figs. 2 and 3 ) can be readily used in the consultation process and compared with the patient's subjective perception.

\section{Actogram interpretation}

An example actogram of a care home resident recorded over a 1-week period is presented in - Fig. 2 .

\section{Case study}

\section{Actigraphy in social jetlag phenomenon}

An extract from a 3-week actigraphy of a patient with social jetlag (SJL) is presented in - Fig. 3.

\section{Actigraphy vs. wearables in sleep medicine practice}

In sleep medicine consultations, patients often present measurements that have been recorded using smartphones or commercially available wearables.

A number of points need to be considered when interpreting these data:

1. These devices are often unvalidated compared to standard sleep medicine

Somnologie 2021 $\cdot 25: 89-98$ https://doi.org/10.1007/s11818-021-00306-8

(c) The Author(s) 2021

J. G. Acker · C. Becker-Carus - A. Büttner-Teleaga - W. Cassel · H. Danker-Hopfe - A. Dück · C. Frohn · H. Hein - T. Penzel · A. Rodenbeck - T. Roenneberg · C. Sauter · H.-G. Weeß • J. Zeitlhofer $\cdot$ K. Richter

\section{The role of actigraphy in sleep medicine}

\section{Abstract}

Actigraphy has been used for more than 60 years to objectively measure sleep-wake rhythms. Improved modern devices are increasingly employed to diagnose sleep medicine disorders in the clinical setting. Although less accurate than polysomnography, the chief advantage of actigraphs lies in the cost-effective collection of objective data over prolonged periods of time under everyday conditions. Since the cost of wrist actigraphy is not currently reimbursed, this method has not enjoyed wide acceptance to date. The present article provides an overview of the main clinical applications of actigraphy, including the recommendations of specialist societies.

Keywords

Circadian rhythm - Sleep-disordered breathing · Insurance, health · Polysomnography . Sleep initiation and maintenance disorders

\section{Stellenwert der Aktigraphie in der schlafmedizinischen Versorgung (englische Version)}

\section{Zusammenfassung}

Seit mehr als 60 Jahren wird die Aktigraphie eingesetzt, um den Schlaf-Wach-Rhythmus objektiv zu erfassen. Zunehmend werden verbesserte moderne Geräte angewendet, um schlafmedizinische Erkrankungen im klinischen Rahmen zu diagnostizieren. Aktigraphen sind zwar weniger genau als die Polysomnographie, aber ihr größter Vorteil liegt in der kostengünstigen Sammlung objektiver Daten über längere Zeiträume unter Alltagsbedingungen. Da die Kosten der Handgelenksaktigraphie derzeit nicht erstattet werden, hat dieses Verfahren bisher keine breite Akzeptanz erlangt. In der vorliegenden Arbeit wird ein Überblick über die wesentlichen klinischen Anwendungen der Aktigraphie sowie über die Empfehlungen der Fachgesellschaften gegeben.

Schlüsselwörter

Zirkadianer Rhythmus · Schlafbezogene Atmungsstörungen · Krankenversicherung $\cdot$ Polysomnographie $\cdot$ Ein- und Durchschlafstörungen methods (actigraphy or polysomnography) [15].

2. Analysis software is subject to a continuous process of review, hampering its use in research projects [16].

3. The software's evaluation algorithms are generally not known or cannot be modified [16].

4. At present, professional actigraphy devices are superior to commercially available wearables in terms of data acquisition and security, as well as their evaluation algorithms [17].

5. The sensors used to measure motor activity are not scientifically validated.

6. The threshold values for measuring motor activity differ from manufacturer to manufacturer. Data visualization is not transparent.
7. Statements on sleep structure and quality that are not scientifically validated are often made based on the measurement of movement frequency.

Thus, medical actigraphy devices continue to be recommended for clinical use [18]. Due to the widespread use of wearables and smartphone apps, their validation will remain an important challenge in the coming years for medical societies, some of which have set up their own task forces [19-21]. 


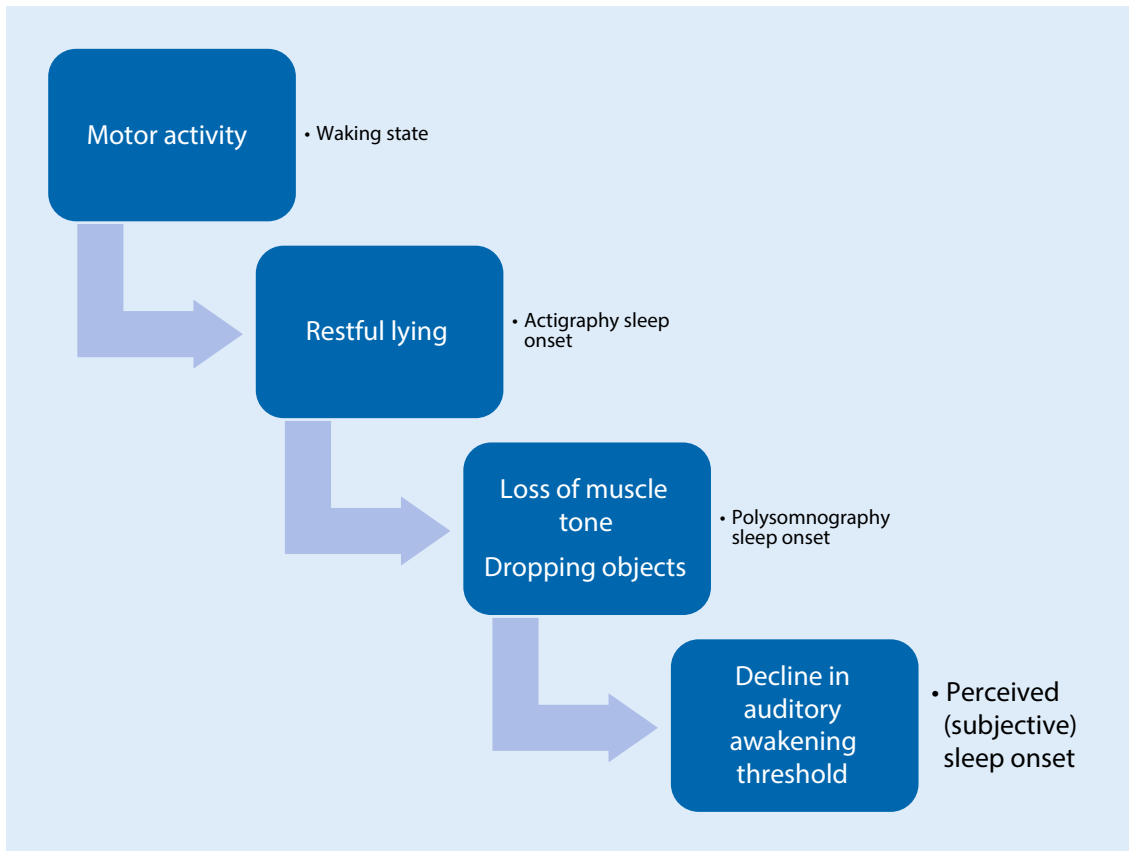

Fig. $1 \Delta$ Sleep onset spectrum. (Adapted from [5]). The recorded sleep duration heavily depends on the measurement method used

\section{Recommendations}

\section{ICSD-3 recommendations on the use of actigraphy}

The current version of the International Classification of Sleep Disorders (ICSD3) recommends actigraphy as a diagnostic tool to supplement classic sleep questionnaires and sleep diaries. Particularly in circadian rhythm disorders does actigraphy have an important role (๑ Table 4).

\section{Recommendations on clinical use of actigraphy (AASM task force)}

In 1995 and 2002, the American Academy of Sleep Medicine (AASM) classified actigraphy as a suitable research instrument but deemed its clinical benefit to be unclear. Manual evaluation of actigraphy data was recommended [23, 24].

In 2018, based on current evidence, the AASM issued new recommendations on the use of actigraphy in clinical routine (• Table 5; [25]).

\section{Reimbursement aspects}

In Germany, actigraphy has not as yet been included in the catalog of services covered by health insurers. To date, it has been billable to the patient as an individual health service (IGeL). A revised catalog of services for privately insured patients includes actigraphy for at least 7 days as a reimbursable service. A policy decision in this regard is pending.

In Switzerland, actigraphy is included in the catalog of mandatory health insurance services, assuming the investigation is carried out at a sleep center recognized by the Swiss Society for Sleep Research, Sleep Medicine, and Chronobiology (SGSSC). If this is not the case, the costs need to be cleared with the health insurance's medical officer before the investigation is performed.

No provision is made in primary care for the reimbursement of actigraphy in Austria at present.

\section{Discussion}

In healthy populations, actigraphy is able to reliably and adequately record total sleep time and sleep onset time within a 24 -h period. Particularly in the case of longitudinal measurements, these results can be placed in a wider context: variances in sleep duration and time of sleep onset; weekly structure (SJL); diagnosis of non-24 syndromes by means of period analysis; estimation of chronotype (relation between time of sleep onset and natural light-dark change [photoperiod] and extent of SJL).

In recent years, actigraphy has been increasingly crystallizing as a clinical tool to diagnose disorders in sleep medicine [26]. In combination with a sleep diary, important information on sleep behavior in the home setting can be obtained over periods of 1-4 weeks with good cost efficiency.

When combined with detailed patient history taking, actigraphy is able to estimate the main sleep-related variables: total sleep time (TST), sleep efficiency (SE), and wake time after sleep onset (WASO) can be determined in numerous sleep disorders.

There are limitations to the use of actigraphy alone for the sleep assessment [27]. It underestimates TST in patients with severe daytime sleepiness, in patients with lower sleep fragmentation, and in patients with more severe sleepdisordered breathing. Actigraphy overestimates TST in patients with high sleep fragmentation, milder severity of sleepdisordered breathing, and short sleepers.

Thus, e.g., motionless wakefulness, as is more common in insomnia patients, is challenging to identify with this method. In order to record the high variability in sleeping patterns in insomnia patients, longer recording periods should be chosen [4].

Actigraphy generally shows good concordance with subjective patient reports on day-night rhythms (e.g., sleep-onset and sleep-offset times). However, there can be significant discrepancy between sleep quality variables such as WASO or SE and the patient's subjective perception. This mismatch needs to be taken into account at the treatment design stage, in order to be able to develop sustainable treatment plans together with the patients.

The automated evaluation algorithms currently used could be further refined in the future once data collection processes have been adapted to additionally use artificial intelligence [28].

In the authors' opinion, the factors that remain essential for the successful application of actigraphy in sleep medicine include the clarification of reimbursement 
Hier steht eine Anzeige.

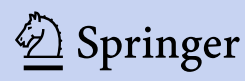




\section{Review}

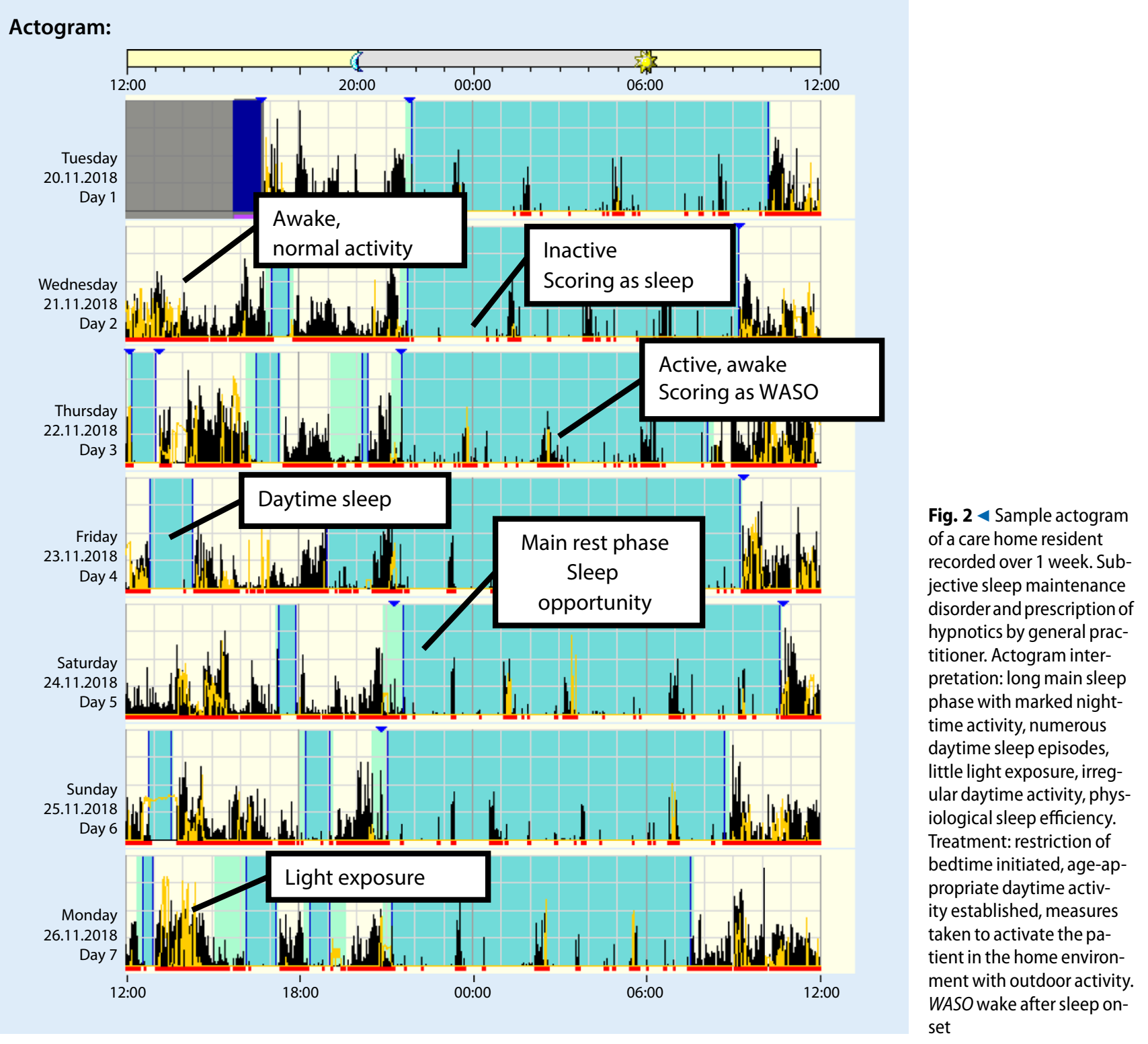




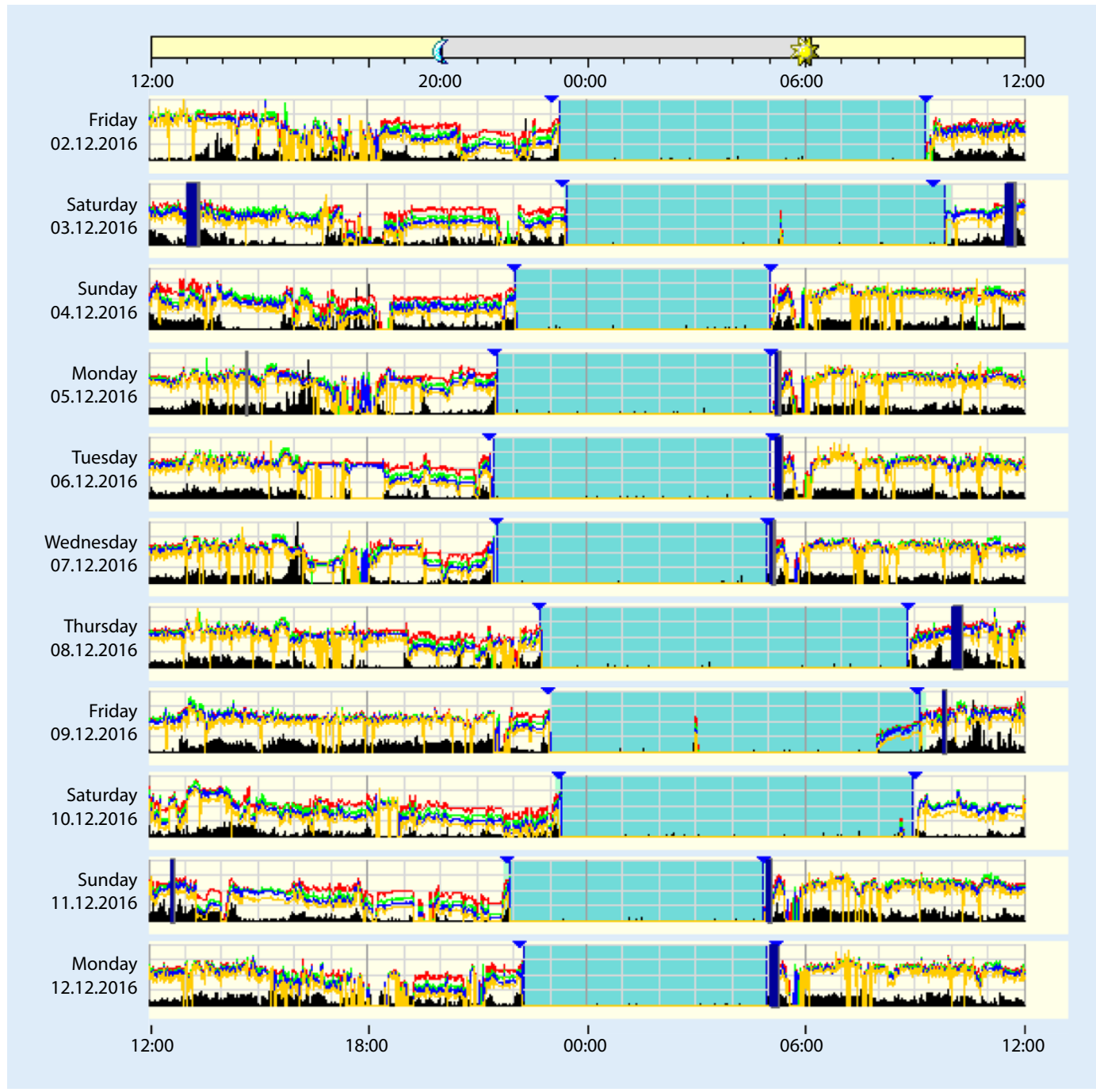

Fig. $3<$ Extract from 3-week actigraphy. The social jetlag phenomenon is evident: patient with daytime tiredness and subjectively perceived non-restful sleep. Visibly longer sleep opportunity at weekends. Sleep history with clearly divergent data, sleep diary not reliably kept. The blue triangles represent actigraph event markers placed by the patient at light out and light on. This makes it possible to measure the length of the sleep attempt (sleep opportunity) 


\section{Review}

Table 4 Recommendations in accordance with the third edition of the International Classification of Sleep Disorders (ICSD-3) [22]

Actigraphy: areas of application (ICSD-3)

Multiple sleep latency test (MSLT)

Idiopathic hypersomnia

Behaviorally induced insufficient sleep syndrome (BISS)

Normal variant: long-sleeper

"Strongly recommended," 1-2 weeks before an MSLT to document a sufficient number of sleep times

Documentation of sleep duration using actigraphy and sleep diary, average over a minimum of 7 days: sleep time $\geq 660 \mathrm{~min} / 24 \mathrm{~h}$

If the correctness of the sleep diary is called into doubt, actigraphy should be performed for at least 2 weeks

Actigraphy to complement sleep diary recommended

Criterion for adult long-sleeper: $>10 \mathrm{~h}$ sleep $/ 24 \mathrm{~h}$ averaged over at least 1 week

Sleep-wake rhythm disorders

If available, actigraphy for at least 7, but ideally 14 days including work/ Delayed sleep-wake phase disorder school days and weekends/leisure time

Advanced sleep-wake phase disorder

Irregular sleep-wake rhythm disorder

Non-24-hour sleep-wake rhythm disorder

Shift work disorder

Circadian sleep-wake disorder not otherwise specified (NOS)

Table 5 Recommendation of the AASM's 2018 task force [25]

Insomnia (adults)

Actigraphy useful to improve the differential diagnosis and when objective estimates of sleep parameters are important for clinical decisionmaking:

Recommended in non-response to cognitive behavioral therapy In cases where an increase in hypnotic dose is required, particularly if the validity of patient reporting is questionable

Helpful in paradoxical insomnia

Insomnia (children)

Actigraphy can be helpful in longitudinal assessments of disease course

There is evidence that actigraphy yields objective data that differ significantly from patient-reported data.

It can also be used in developmental disorders and autism spectrum disorders.

Actigraphy is not subject to reporting bias on the part of the carer

Circadian rhythm sleep-wake disorders (adults)

Actigraphy is particularly helpful in the assessment of sleep-onset and sleep-offset times, as well as in the evaluation of treatment response

Circadian rhythm sleep-wake disorders (children) It can also be used in developmental disorders and autism spectrum disorders.

Actigraphy can record objective data that differ significantly from carerreported data (sleep diary, etc.)

Actigraphy that can be integrated in polygraphic devices

This can improve the estimation of total sleep time compared to polygraphy alone

Actigraphy to monitor sleep duration prior to carrying out a multiple sleep Actigraphy can be performed 7-14 days prior to conducting latency test (MSLT)

polysomnography/MSLT in order to rule out insufficient sleep syndrome

Investigation of insufficient sleep syndrome

Recording over a period of 2-3 weeks is recommended depending on the clinical problem

The majority of studies available to date have demonstrated a significant difference (over- or underestimation of the number of periodic leg movements) compared to standard electromyography

Strong recommendation against the use of actigraphy instead of electromyography in the investigation of periodic leg movements

issues and the further development of evaluation standards.

\section{Corresponding address}

\section{Dr. med. Jens G. Acker, MBA}

Clinic for Sleep Medicine Bad Zurzach and Zurich Airport

Badstraße 33, 5330 Bad Zurzach, Switzerland j.acker@ksm.ch
Acknowledgement. The publisher would like to thank Christine Rye (Windsor, UK) for translating the article from German into English.

\section{Declarations}

Conflict of interest. J.G. Acker, C. Becker-Carus, A. Büttner-Teleaga, W. Cassel, H. Danker-Hopfe, A. Dück, C. Frohn, H. Hein, T. Penzel, A. Rodenbeck, T. Roenneberg, C. Sauter, H.-G. Weeß, J.Z Zeitlhofer, and K. Richter declare that they have no competing interests.

For this article no studies with human participants or animals were performed by any of the authors. All studies performed were in accordance with the ethical standards indicated in each case.

Open Access. This article is licensed under a Creative Commons Attribution 4.0 International License, which permits use, sharing, adaptation, distribution and reproduction in any medium or format, as long as you give appropriate credit to the original author(s) and 
Hier steht eine Anzeige.

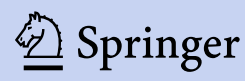


the source, provide a link to the Creative Commons licence, and indicate if changes were made. The images or other third party material in this article are included in the article's Creative Commons licence, unless indicated otherwise in a credit line to the material. If material is not included in the article's Creative Commons licence and your intended use is not permitted by statutory regulation or exceeds the permitted use, you will need to obtain permission directly from the copyright holder. To view a copy of this licence, visit http://creativecommons.org/licenses/by/4.0/.

\section{References}

1. Tryon WW (1996) Nocturnal activity and sleep assessment. Clin Psychol Rev 16:197-213. https:// doi.org/10.1016/0272-7358(95)00059-3

2. Hein H, Küchler G, Anfang I (2008) Aktographie zur Erkennung von Schlaf-Wach-Rhythmen auf Segelbooten. Somnologie 12:46. https://doi.org/ 10.1007/s11818-008-1001-0

3. Ibáñez V, Silva J, Cauli O (2018) A survey on sleep assessment methods. Peer J 6:e4849. https://doi. org/10.7717/peerj.4849

4. Van Someren, Eus JW (2007) Improving actigraphic sleep estimates in insomnia and dementia: how many nights? J Sleep Res 16:269-275. https://doi. org/10.1111/j.1365-2869.2007.00592.x

5. Tryon WW (2004) Issues of validity in actigraphic sleep assessment. Sleep 27:158-165

6. Kawada T(2013) Sleep parametersfromactigraphy and sleep diary: is the agreement important for sleep study? Sleep Med 14:298-299. https://doi. org/10.1016/j.sleep.2012.09.016

7. Zinkhan M, Berger K, Hense S, Nagel $M$ et al (2014) Agreement of different methods for assessing sleep characteristics: a comparison of two actigraphs, wrist and hip placement, and self-report with polysomnography. Sleep Med 15:1107-1114. https://doi.org/10.1016/j.sleep. 2014.04.015

8. Kushida CA, Chang A, Gadkary C, Guilleminault Cet al (2001) Comparison of actigraphic, polysomnographic, and subjective assessment of sleep parameters in sleep-disordered patients. Sleep Med 2:389-396

9. Ancoli-Israel S, Martin JL, Blackwell T, Buenaver L et al (2015) The SBSM guide to actigraphy monitoring: clinical and research applications. Behav Sleep Med 13:S4-S38

10. LampA, Rasmussen I, CookM, Smith RS et al (2019) 0312 creating A standardized procedure for sleep measured by actigraphy in aviation field studies. Sleep 42:A128-A128. https://doi.org/10.1093/ sleep/zsz067.311

11. Kripke DF, Hahn EK, Grizas AP, Wadiak KH et al (2010) Wrist actigraphic scoring for sleep laboratory patients: algorithm development. J Sleep Res 19:612-619. https://doi.org/10.1111/j. 1365-2869.2010.00835.x

12. Sadeh A (2011) The role and validity of actigraphy in sleep medicine: an update. Sleep Med Rev 15:259-267. https://doi.org/10.1016/j.smrv.2010. 10.001

13. Winnebeck EC, Fischer D, Leise T, Roenneberg T (2018) Dynamics and Ultradian structure of human sleep in real life. Curr Biol 28:49-59.e5. https://doi. org/10.1016/j.cub.2017.11.063

14. Meltzer LJ (2020) Using actigraphy for the assessment of sleep/wake disorders: C-06: behavioral sleep medicine: the latest trends and promising developments shaping our practice in the future

15. Depner CM, Cheng PC, Devine JK, Khosla S et al (2020)Wearable technologies for developing sleep and circadian biomarkers: a summary of workshop discussions. Sleep. https://doi.org/10.1093/sleep/ zsz254

16. Dominick GM, Winfree KN, Pohlig RT, Papas MA (2016) Physical activity assessment between consumer-and research-grade accelerometers: a comparative study in free-living conditions. JMIR Mhealth Uhealth 4:e110. https://doi.org/10.2196/ mhealth.6281

17. Meltzer LJ, Hiruma LS, Avis K, MontgomeryDowns $\mathrm{H}$ et al (2015) Comparison of a commercial accelerometer with polysomnography and actigraphy in children and adolescents. Sleep 38:1323-1330. https://doi.org/10.5665/sleep. 4918

18. Insana SP, Gozal D, Montgomery-Downs HE (2010) Invalidity of one actigraphy brand for identifying sleep and wake among infants. Sleep Med 11:191-196. https://doi.org/10.1016/j.sleep.2009. 08.010

19. ScottH, LackL, Lovato N (2020) A systematic review of the accuracy of sleep wearable devices for estimating sleep onset. Sleep Med Rev 49:101227. https://doi.org/10.1016/j.smrv.2019.101227

20. de Zambotti M, Cellini N, Menghini L, Sarlo M et al (2020) Sensors capabilities, performance, and use of consumer sleep technology. Sleep Med Clin 15:1-30. https://doi.org/10.1016/j.jsmc.2019.11. 003

21. Bhat S, Ferraris A, Gupta D, Mozafarian M et al (2015) Is there a clinical role for Smartphone sleep Apps? Comparison of sleep cycle detection by a Smartphone application to polysomnography. J Clin Sleep Med 11:709-715. https://doi.org/10. 5664/jcsm.4840

22. American Academy of Sleep Medicine (2014) International classification of sleep disorders Third Edition: ICSD-3, 3rd edn. American Academy of Sleep Medicine, Darien

23. Thorpy M, Chesson A, Derderian S (1995) Practice parameters for the use of actigraphy in the clinical assessment of sleep disorders. American Sleep Disorders Association. Sleep 18:285-287. https:// doi.org/10.1093/sleep/18.4.285

24. Littner M, Kushida CA, Anderson WM, Bailey D et al (2003) Practice parameters for the role of actigraphy in the study of sleep and circadian rhythms: an update for 2002. Sleep 26:337-341

25. Smith MT, McCrae CS, Cheung J, Martin JL et al (2018) Use of actigraphy for the evaluation of sleep disorders and circadian rhythm sleepwake disorders: an American Academy of Sleep Medicine clinical practice guideline. J Clin Sleep Med 14:1231-1237. https://doi.org/10.5664/jcsm. 7230

26. Stone KL, Ancoli-Israel S (2017) Actigraphy. In: Kryger MH, Roth T, Dement WC (eds) Principles and practice of sleep medicine. Elsevier, Philadelphia, pp 1671-1678.e4 https://doi.org/10.1016/B9780-323-24288-2.00171-9

27. Berry RB, Wagner MH (2015) Indications for polysomnography, portable monitoring, and actigraphy. Sleep Med Pearls. https://doi.org/10 1016/B978-1-4557-7051-9.00010-3

28. ChoT, Sunarya U, Yeo M, Hwang B etal (2019) DeepACTInet: end-to-end deep learning architecture for automatic sleep-wake detection using wrist Actigraphy. Electronics 8:1461. https://doi.org/10. 3390/ELECTRONICS8121461
Springer Medizin Podcast

Medizin für Gesundheitsprofis

Der Podcast von SpringerMedizin.de geht seit Juli 2020 spannenden Fragen aus der Welt der Medizin nach immer freitags erweitert eine neue Folge das bereits bestehende OnlineAngebot.

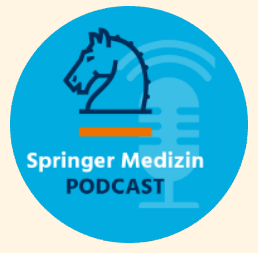

"Mit unserem

Podcast möch-

ten wir all jene ansprechen, die sich auf medizinische Themen in einer, gewissen

Flughöhe' einlassen möchten", erklärt Dr. Erik Heintz, Chefredakteur von SpringerMedizin.de das neue Format. "Gemeint sind damit Menschen, die sich nicht mit medizinischem Halbwissen zufrieden geben und gerne mehr wissen möchten. Daher legen unsere Redakteurinnen und Redakteure in München und Heidelberg vor allem auf den inhaltlichen Anspruch großen Wert. Unter Bezugnahme auf neue Studien, neue Erkenntnisse und praxisrelevantes Wissen bereiten wir jeden Podcast gründlich vor. Die Themen drehen sich um Gesundheit, Krankheit, Diagnostik, Therapie und Prävention, zu denen wir unsere Fachexpertinnen und Fachexperten aus verschiedenen medizinischen Fachgebieten hinzuziehen.

So entstehen abwechslungsreiche Folgen, die sowohl detailliert Leitlinien abarbeiten, der Evidenz von neuen Studienergebnissen auf den Grund gehen aber auch die Hintergründe zu Erkrankungen und Therapien aufschlüsseln - sodass einerseits die ärztliche Praxis erleichtert und konkrete Tipps für die alltägliche Arbeit vermittelt werden, andererseits aber auch der Horizont über das eigene Fachgebiet hinaus erweitert werden kann.

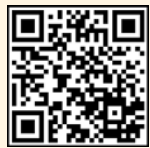

www.springermedizin.de/podcast 